\title{
Incorporating Engineering in a High School FACS and Chemistry Class
}

Bonnie Boyd (bonnie.boyd@spps.org) Saint Paul Public Schools

AnnMarie Thomas (apthomas@stthomas.edu) University of St. Thomas

Alex Zierden (zierd028@d.umn.edu) University of St. Thomas/U of Minnesota Duluth

\begin{abstract}
This paper presents the preliminary development of engineering units for a year-long high school Food Science and Chemistry course. While the course is not intended as an engineering course, we explored ways that students could be introduced to the engineering design process, and other engineering concepts, as a way to motivate interdisciplinary thinking and inspire future exploration. As this project is in its early stages, we will present three potential units that incorporate engineering while meeting Next Generation Science Standards and Minnesota State Science Standards related to this course.
\end{abstract}

\section{Science and Engineering at AGAPE}

AGAPE is a small urban public high school in Saint Paul, Minnesota that was established more than fifty years ago, offering a secondary educational program to teens who are pregnant and/or parenting. The population, all female, is very diverse: 30\% Black, 30\% Asian, 30\% Hispanic, 1\% Native American and a 7-10\% white population. Of the overall population, 30\% are multiple language learners. These young women are typically first generation Americans with very strong cultural ties. Typically, they are the primary caregivers to their families. When surveyed about possible careers after high school, most students will state they want to be nurses or elementary teachers.

Five years ago, AGAPE joined an existing Saint Paul Public high school FIRST Robotics team. For several years, a small group of students participated in the yearly competition. Each group of young women enthusiastically joined the team wanting to build a robot. Each year the group faded into the background of supporting the team by doing clerical and administrative type of jobs, while the majority of male team members built the robot. Engineering terms and protocol seemed to intimidate the young women. There was a sense of "they know what they are doing, so I'll do the other job” mentality. Even with FIRST Robotic emphasis on inter and intra team building and collaboration, these young women had mind-sets that were deeply ingrained with a “can” and “cannot”.

Over several years, AGAPE has aligned science classes to meet the state requirements by implementing high school chemistry and biology classes. AGAPE has experienced many of 
these young women grow their mind-sets. Many enter the classroom and expect to fail, because "chemistry is hard." Yet, they flourish into problem solvers and master Minnesota state science standards. Every year the number of AGAPE graduates continues to increase. In 2004 AGAPE graduated 16 students, 2008, 32 students, and this year, 41 seniors graduated. Of these graduates, $81 \%$ were accepted into 2-year and 4-year colleges, most still seeking caregiving careers. AGAPE's staff contributes the increase in student success due to the support and focus on college and career readiness, and an overall increase in academic rigor. Students want to do well and have careers. Yet, there seems to be a lack of knowledge about career options outside of the "normal" highlighted careers that are often talked about, such as teaching, nursing etc. AGAPE is a perfect setting to establish science classes to support Food Science and to incorporate engineering processes, as well as highlighting careers in food engineering. The idea is to create and implement a series of science classes within this small environment that can eventually be expanded into the major mainstream schools.

\section{Engineering Science Standards and Cooking}

The Minnesota state standards to graduate high school are fairly concrete concerning what they require from the broad world of sciences and technology. As they are, these standards require a full course load of liberal arts classes, as well as three years of math and at least two years of science, including biology and the student's choice of chemistry or physics. However, as found on the document "Minnesota Academic Standards" produced by the Minnesota Department of Education (2009), they emphasize that there are actually four science disciplines that need to be taught sufficiently to students by the time they graduate. These four disciplines are the Nature and Science of Engineering, Earth and Space Science, Life Science, and Physical Science ${ }^{1}$ (p. 2). However, they follow up that recognition with saying that "It is important to note that the content and skills in The Nature of Science and Engineering are not intended to be taught as a standalone unit or an isolated course, but embedded and used in the teaching, learning, and assessment of the content in the other strands"1 (Minnesota Department of Education, 2009, p. 2). This means that the two years of science classes in high school have a heavy weight to carry; they must successfully explore and teach four realms of science with only two classes. Engineering must be consciously woven into the curriculum in order for students to get the full exposure that they need to be prepared to choose career and study paths as they graduate high school. For these reasons, we have chosen to actively insert engineering concepts into common high school science classes to help broaden student's experiences with science and to better meet the standards presented by the Minnesota Department of Education. We are achieving these goals primarily through connecting cooking within the courses of family and consumer science, chemistry, and biology.

Cooking is the method of choice, for its popularity amongst the general public, alignment with the caregiving courses AGAPE students are interested in, and its growing domains in the college setting. Several schools are starting to include food sciences in their curriculum for the sake of 
exposing more students to the sciences via a creative avenue. For example, Harvard recently offered a free online certificate course through their site edx.org that specifically focuses on cooking and science. That class can be found on their online site at the number SPU27x, where their syllabus will tell you that "At the end of the course, students will be able to explain how a range of cooking techniques and recipes work, in terms of the physical and chemical transformations of food”2 (Michael P. Brenner, Pia Sörensen, and David Weitz, 2012, pg. 1). The goals of that class being to teach the students chemistry through cooking and food processing. Professors and students at the University of St. Thomas have also spent time working with Haiti to create breadfruit flour products to help feed people in a cost effective way. Particularly, a large group of freshmen students recently took on a breadfruit dryer engineering design project to give them exposure to real world engineering projects and to open them up to engineering in a different, unique application. The University has also held a Peace Engineering contest to get public help with this engineering project for Haiti ${ }^{3}$ (Engebretson, K., 2012, n. pg.) Schools like the Illinois Institute of Technology ${ }^{4}$, Sheffield Hallam University of the United Kingdom ${ }^{5}$, Shahjalal University of Science and Technology of Bangladesh ${ }^{6}$, and others have adopted Food Engineering specific four year degrees for students

In addition to schools taking interest in food engineering, cooking is popular among the general audiences as well. A poll published by Harris Interactive shared that "Half of Americans (50\%) say they watch TV shows about cooking very often or occasionally..."7 The article continued on with saying that those numbers are not limited to the older generations either. Harris' poll found that $43 \%$ of those aged $18-33$ watch cooking shows often or occasionally ${ }^{7}$. This means that a significant percentage of school attending students have interest in cooking shows, and therefore could have increased interest in a science course based on its connections and applications to their affinity for cooking.

Both the spiked interests among the general public and the growing popularity of food engineering college level programs lead into offering similar opportunities to high school level students. High school courses can promote the development of academic interests and help students choose career paths based on their positive classroom experiences. For these reasons, we have chosen to work through three high school required classes and connect the aspects of science with food to create a more creative and nurturing learning experience for students who might be intimidated by the science portions. The three chosen classes are Chemistry, Biology, and finally, Family and Consumer Science. Doing this will give students the opportunity to both learn more thoroughly by providing more real life, relatable connections for the students to utilize in their learning, as well as better hit the four science requirements for high school to include more applicable engineering ideas. This is beneficial because it has the capabilities of creating more positive learning experiences, and it can help created increased interest in and awareness of an internationally growing college degree path. 


\section{Applying Engineering to the Curriculum}

The goal of including engineering in Family and Consumer Science classes is purely to introduce engineering concepts to the students at AGAPE and not to detract from the curriculum already providing in the class. The objective is to supplement the class with more ideas, and to inspire engineering in a creative way. If the cooking class becomes too engineering intensive, it could easily turn into an intimidating class rather than a fun one, and have the reverse of the desired inspiring effect. For that reason, the application of these engineering ideas is more geared towards discussion and teaching the engineering design process rather than teaching full engineering rules and methods. The students will find the engineering concepts woven in and interconnected with the material they’re learning for their Family and Consumer Science class.

The first engineering topics are introduced at the very beginning of the semester, right along with the introductory cooking lessons. The first few kitchen lessons are about kitchen equipment and kitchen safety. The engineering ideas here are about having the students begin to analyze what various tools are and how they're useful in that setting. These topics vary from identifying whether certain utensils are helpful for various tasks, to a mini design project where the students dream up their own kitchen equipment to fit their cooking needs. For the mini design project, the AGAPE students will be given a short lesson on an engineering design process. They will go through the steps of defining the cooking problem they want to solve, do some short research on similar products that perform similar duties, then write up the specifications for their solution. From there, they will brainstorm a handful of solutions to the problem. They'll evaluate them with a ranking system of how well each solution meets the needs and specifications of the problem. Then, with the rankings in mind, choose a solution that would best solve their problem. The problem the students will solve could be done as one team goal for the whole group, or have a few problems to be solved by a number of smaller groups. This project could be used with a multitude of predetermined problems, which gives it great accessibility to whatever the curriculum goal is. The students could try to invent a new way to make eggs or find a better tool to scoop out soft foods, or other topics related to making kitchen tools more efficient.

A similar engineering design process can be seen and compared to in the general process of cooking as well. A meal starts by the cook determining what their goal is to create, and looking up what types of ingredients will help accomplish the product they desire. Then, the cook will figure out how much of the food they need to make versus what they have for ingredients. This would be equivalent to laying out the specifications of their cooking project. They'll find recipes that meet their goals and evaluate each one for ease, accessibility, and quality. Next, they'll choose a recipe to go with and create it. This could be considered making a prototype. Upon the food being finished, the cook will try their product and decide if the recipe was successful or not. If it's decided that a few modifications could be made to improve it, they will be noted and changed the next time that recipe is made. By this example, it can be seen that cooking goes through a process that mirrors the engineering process. This methodology can be pointed out to 
the students with every cooking project they do, and every project can be finished with a short analysis of their end result and any modifications they would make for future trials of this recipe. It's a very simple and subtle activity, but by consistently going through this exercise with every project, students can ingrain the engineering design process in their everyday projects by subconsciously going through these engineering design steps to accomplish tasks effectively.

Throughout the course, we would also like to incorporate discussion topics that also get the students thinking about how engineering and cooking also relate to chemistry and biology. Ideally these topics would be more student directed with the students coming into the discussion period with an article or previous topic of interest. In discussion, the students would have the opportunity to talk about how all the science curriculum they've learned applies in real life. It could be about anything from the progress and goals of creating genetically modified organisms for our world, to how eating a cheeseburger provides a chain reaction of events relating to chemistry and biology. Topics and resources about how a cheeseburger is broken down to make bonds, which is a chemistry subject, to how what the burger is made into fuels your cells and you body, which is a biology topic, provide a very clear and simple analogy of how relatable chemistry and biology are to cooking. The idea here is that we want to show the AGAPE students how applicable the curriculum is to the real world and that chemistry, biology, and engineering are already parts of their everyday lives, whether they recognize it as such or not.

The end objectives of this class collaboration are simple. We want to provide the AGAPE students with a creative and unique experience of the sciences to make it less intimidating or undesirable. The idea is to show them that science isn't just part of a intimidating far off world that they can't be a part of. We want to show science is a part of their everyday life, and they can be involved in creating it and making it too. We aren't looking to create an engineering class about cooking and science. We're looking to take Family and Consumer Science and supplement it with engineering ideas to make science seem less intimidating to those who otherwise wouldn't experience it. By exposing the AGAPE students to science in a non-threatening way, it is our hope that they will be inspired with more of a "can do" attitude to excel in science classes and investigate engineering and science based fields. The goals of incorporating engineering into cooking are to expose the students to more ideas and options than they would've felt they had otherwise. We want our AGAPE women involved in all career fields, and we want to give them the opportunities to achieve whatever they choose to lead their lives with.

\section{Bibliography}

1 Minnesota Department of Education (2009). Minnesota Academic Standards: Science K-12 2009 Version. Retrieved from education.state.mn.us/mde/index.html 
2 Brenner, M. P., Sörensen, P., \& Weitz, D. (2012). SPU 27x Science and Cooking: From Haute Cuisine to Soft Matter Science. Retrieved from https://courses.edx.org/courses/HarvardX/SPU27x/2013_Oct/info

3 Engebretson, K. (2012). Dr. Camille George Engineers the Future of Breadfruit. Retrieved from http://www.stthomas.edu/news/camillegeorgeandthefutureofbreadfruit/

$4 \quad$ Armour College of Engineering (2014). BS Chemical Engineering - MAS Food Process Engineering. Retrieved from http://engineering.iit.edu/programs/co-terminal/bs-chemical-engineering-mas-food-processengineering

$5 \quad$ Sheffield Hallam University (2014). MEng Food Engineering. Retrieved from http://www.shu.ac.uk/prospectus/course/1247/further/

6 Shahjalal University of Science and Technology (2014). Department of Food Engineering and Tea Technology. Retrieved from http://www.sust.edu/departments/ftt

7 Corso, Regina (2010). EVOO and Yummy! 30 Minute Meals is America’s Favorite Cooking Show. Retrieved from http://www.harrisinteractive.com/vault/HI-Harris-Poll-Cooking-Shows-2010-07-29.pdf 